\title{
INTRAOPERATIVE AND EXTERNAL RADIOTHERAPY IN RESECTED GASTRIC CANCER: UPDATED REPORT OF A PHASE II TRIAL
}

Felipe A. Calvo*, J. Javier Aristu*, Ignacio Azinovic*, Oscar Abuchaibe*, Luis Escude*, Rafael Martinez*, Enrico Tangco*, Jose L. Hernandez $\dagger$, Fernando Pardo $\dagger$ and Javier Alvarez-Cienfuegos $\dagger$.

* Service of Radiotherapy, Department of Oncology.

$\dagger$ Department of General Surgery.

Clinica Universitaria de Navarra, School of Medicine, University of Navarra, Pamplona 31080, Spain

\begin{abstract}
From September 1984 to August 1991, 48 evaluable patients with resected gastric cancer and apparent disease confined to locoregional area were treated with intraoperative electron beam boost to the celiac axis and peripancreatic nodal areas (15 Gy) and external irradiation (40 to 46 Gy in 4 to 5 weeks ) including the gastric bed and upper abdominal nodal draining regions. At the time of evaluation for IORT, the disease was primary in 38 cases, recurrent but resectable in four (anastomosis), and unresectable in four (nodal). Post operative complications were reversible. Acute tolerance to the complete treatment program was acceptable. Late complications included lifethreatening events: Six episodes of gastro intestinal bleeding (three of them had an arteriographic documentation of arterioenteric fistula) and nine with severe enteritis (five required reoperation). Other long-term treatment related complications were six cases of vertebral collapse. The median follow-up time for the entire group is 22 months. Locoregional recurrence / persistence of disease has been identified in five patients (three with residual and /or recurrent postsurgical tumor). Systemic tumor progression has been detected in 15 patients (11 in intra-abdominal sites). Overall actuarial survival for patients with positive or negative serosal involvement was $33 \%$ versus $56 \%$. It is concluded that the treatment program described is able to induce a high locoregional tumor control rate $(100 \%)$ when used strictly in an adjuvant setting and might control long term, a small portion of patients not amenable for curative surgery ( 2 out of 8 patients with confirmed residual post-surgical disease). Gastrointestinal bleeding and enteritis are findings that indicate treatment intensity at the upper limits of tissue tolerance. Assessment of long term tolerance of pancreatic parenchima and large blood vessels (tissues included in the IRORT field) are pending for longer follow-up and the appropriate selective studies.
\end{abstract}

\section{KEY WORDS}

Intraoperative radiotherapy, External beam radiotherapy, Gastric cancer. 


\section{INTRODUCTION}

Studies analyzing the patterns of tumor recurrence following surgery for gastric cancer have consistently shown a certain tendency to develop involvement of locoregional areas. Reports of autopsy studies (46), planned reoperation series (23) and retrospective reviews (38) identified the gastric bed, nodal regions, duodenal or anastomosis stump as the locoregional areas and structures with higher risk of tumor relapse. The locoregional recurrence rate is estimated in excess of $35 \%$ for those patients with serosal and/ or nodal involvement (30).

Radiotherapy as a locoregional adjuvant treatment modality has been pursued in multidisciplinary protocols $(15,28,44)$. The limited tolerance of upper abdominal organs and tissue structures $(22,37)$, and the complexity to define the target volume for adequate postoperative radiotherapy in gastric cancer patients, are some of the critical issues to consider for the integration of radiotherapy in multimodal approaches $(16,21)$.

Intraoperative radiotherapy (IORT) is a treatment modality able to deliver accurately a high dose of radiation to upper abdominal areas, while protecting some normal tissues (2). IORT has been successfully used in the treatment of gastric cancer patients $(1,3)$. External beam radiotherapy techniques for post-gastrectomy patients have been refined in the last decade (31). The combination of an IORT boost to a large external irradiation volume constitutes an intense locoreginal treatment program, particularly attractive to be tested in patients with initially localized and resectable gastric cancer. This study analyzes the results obtained in a clinical trial using the combination surgery with or without gastrectomy (isolated recurrences were accepted for the trial), IORT and external beam irradiation. The preliminary findings were previously reported in an earlier description of technical features and clinical results analysis (12).

\section{METHODS AND MATERIALS}

From September 1984 to August 1991, 56 patients with gastric neoplasms entered in a Phase oriented clinical therapeutic trial combining gastrectomy, IORT (15 Gy) and external beam irradiation ( 46 Gy in 5 weeks). Eight patients were excluded for this analysis: four had metastatic disease outside the IORT field (one liver, one peritoneal, two positive peritoneal cytology), three had histologies other than adenocarcinoma (two lymphomas and 1 leiomyosarcoma) and one patient was lost to follow-up early after the initial treatment.

The treatment protocol and technical aspects have been described in detail in a previous report (12). In summary, patients with localized gastric adenocarcinoma were approached by gastrectomy, nodal sampling, IORT electron boost to the celiac axis and pancreatic nodes (15 Gy) (Fig. 1), and external beam irradiation to a large upper abdominal volume including the gastric bed and nodal regions (including the celiac axis, peri pancreatic, heptic and splenic hilum, and para aortic) ( Fig. 2).

The IORT target volume was encompassed with a single-field using circular cones and bevelled ends (Fig. 3). The range of electron energies available was from $6 \mathrm{MeV}$ to 20 $\mathrm{MeV}$. The external irradiation was delivered to all patients using $15 \mathrm{MV}$ photon beams, 
AP-PA fields. The fields were shaped with appropriate shielding blocks to confine the radiation beam to the desired anatomic area. The target volume encompassed the areas considered at risk or known to have residual disease. The IORT program in our institution requires the transport of the patient from the surgical theatre to the room containing the linear accelerator. This means regularly the addition of 50-60 min. to the surgical time. Transportation time does not usually exceed 7 min (each way).

Among the 48 patients evaluable in the trial, the age range from 34 to 76 years old (median 58 years). There were 35 males and 13 females. Karnofsky performance status was equal or superior to $70 \%$ in 37 patients $(77 \%)$. The main complaint was abdominal pain in 25 patients at the time of diagnosis (Table 1). All tumors were reported as adenocarcinoma except two cases of anaplastic histologies. In 31, the subtype was either poorly differentiated and/or diffuse $(65 \%)$. The most frequent tumor site involvement within the stomach was distal (involving the antropyloric area or more zones, in 22 cases, $46 \%$ ). Seven patients had an anastomotic recurrence in the stump of the previous gastrectomy (four gastric cancer and three benign ulcers). Four patients were approached with surgery, IORT, and external irradiation because of nodal recurrences in the celiac axis area following a previous gastrectomy. In 27 pathology specimens, nodal metastasis were observed. The number of nodes studied ranged from 2 to 53 with a median of 12 nodes per specimen. The number of tumor involved nodes ranged from 1 to 29 with a median of three metastatic nodes. In the uninvolved nodal group, the total number of nodes studied ranged from 4 to 26 with a median of 10 free of malignant disease ( Table 2 ).

The tumor extension through the gastric wall was available in 44 specimens studied (four patients were treated for nodal recurrences while free of mucosal or anastomotic relapse). In 31 cases, the tumor involved the serosa and in the remaining 13, the tumor did not extend further than the muscularis propia. The resection limits of gastrectomy along the digestive tube were microscopically involved in seven patients: five the esophageal and two the duodenal border. In 13 patients, components of extra gastric malignant disease were identified. Following the recent modification of the staging system for gastric cancer (33), the tumor stages were stratified as follows: 16 Stage I-II, 19 Stage III, and 13 Stage IV. In 18 patients, the presence of two poor prognostic features was associated (metastatic nodes plus serosal involvement).

Technical treatment aspects are summarized in Table 3. The surgical procedure consisted in total gastrectomy in 36 cases, partial in eight and exposure to the IORT beam of a nodal recurrence (without resection) in four cases. The IORT technique required the use of a single field in 47 procedures. The exception was one case in which two IORT fields were used in a large tumor involving the fundus and approached through a thoraco phreno-laparotomy: the fields encompassed the gastric bed and celiac axis in two different but adjacent volumes. The cone size employed ranged from 5 to 10 $\mathrm{cm}$ in external diameter (the cone wall thickness is $3 \mathrm{~mm}$ ). The most frequent cone size used was $8 \mathrm{~cm}$. The electron energies selected have been in the lower spectrum available $(6$ and $9 \mathrm{MeV})$ in patients with assumed microscopic residual disease. The higher energies were selected in the cases with known macroscopic residual disease (including all cases with nodal relapses in the celiac axis area). Minor variations in the IORT dose delivered were accepted in the trial. The exceptions were three cases with suspected early tumor stages treated with 10 Gy IORT and one case of massive recurrence in the celiac axis with $20 \mathrm{~Gy}$. In five patients with early tumor stages 
external irradiation was omitted. In the remaining 43 patients receiving external beam radiotherapy four had this treatment component preoperatively and 39 postoperatively following tumor resection or exposure of recurrences to IORT. The four patients treated with preoperative radiotherapy had primary tumors which were considered technically unresectable in a prior laparotomy. In all four cases, the external irradiation was administered with simultaneous chemotherapy (carboplatin $55 \mathrm{mg} / \mathrm{m} 2$ iv and 5 fluorouracil $1000 \mathrm{mg} / \mathrm{m} 2$ iv in $24 \mathrm{hr}$ continuous infussion with a maximum of $1500 \mathrm{mg} /$ day on days 1-3 and 20-22 of irradiation).

Chemotherapy was administered to 13 patients in this trial. Four simultaneously with external preoperative radiotherapy for unresectable locally advanced primary tumors. Three additional patients received systemic neoadjuvant chemotherapy for primary locally advanced (cisplatin $20 \mathrm{mg} / \mathrm{m} 2$ iv and 5-fluorouracil $1000 \mathrm{mg} / \mathrm{m} 2$ iv continuous infusion with a maximum of $1500 \mathrm{mg}$ / day on days 1 to 5 repeated every 28 days for 2 to 4 cycles).

All patients treated preoperatively were resected at the time of surgical evaluation. Ten patients with poor prognostic features (residual disease following gastrectomy, extensive nodal involvement, diffuse undifferentiated subtypes or a combination of these) were treated with adjuvant chemotherapy using platinum compounds and iv infusion of 5-fluorouracil for 4 to 6 courses, or until disease progression. ( Table 3 )

Patients were followed every 3 months in outpatient consultation. Routine blood tests and physical examination were performed. CT scans of the abdomen were done twice a year or when symptoms appear. Episodes of gastrointestinal bleeding were urgently studied through endoscopy and selective abdominal arteriography. Patients developing progressive malignant disease were studied to establish the patterns of recurrence. Autopsy studies were requested in eight patients dying in the hospital: five necropsies were performed. Survival curves are calculated using the corrections of the actuarial method.

\section{RESULTS}

\section{Toxicity and complications}

In the immediate postoperative period, there were several complications observed, but no postoperative mortality. The morbidity consisted in five infections requiring specific treatment (five pneumonias and three abdominal abscess), one case of pulmonary emboli, three pancreatic fistula, (one distal pancreatectomy and one Whipple resection), one gastrointestinal bleeding and one suture dehiscence requiring reoperation.

In the late follow-up period (more than 3 months from surgery) several normal tissue changes were observed and will be described in detail. Vertebral collapse was observed in six patients, involving L1, L2, or T12 vertebral bodies. The finding was asymptomatic in three patients and four required anti-inflammatory oral therapy, one an orthopedic device and one was treated with surgical stabilization. In four patients, hypodense lesions developed in the liver and specific studies with isotopic labelled erythrocytes suggested the diagnosis of hemangiomas. Three patients required esophageal dilatations 
because of symptomatic stenosis of the area of mechanic esophagojejunal suture. One episode of liver infarction (in a terminal patient) and one of cholangitis were observed. The most relevant toxicity and complication observed was enteritis. This was defined in the present trial as any evidence of digestive alteration in the follow-up period, including persistent abdominal pain or discomfort, malabsorption, food-intake intolerance, together with evidence of radiologic changes compatible with intestinal wall and/ or mucosal edema, or areas of bowel stenosis. Enteritis was identified as symptomatic in nine patients (four had been treated with chemotherapy). Two of the nine patients required reoperations: one due to subocclusive digestive crisis and another from bowell wall perforation. One patient is alive with no evidence of disease at 26 months follow-up. Five enteritis were associated with gastrointestinal bleeding. Three patients were diagnosed through emergency arteriography of arterioenteric fistulas and were reoperated. In these patients the origin of the bleeding was the left gastric artery stump. The time from the first surgery to reoperation from this complication was 3, 7 and 12 months. One patient who underwent reoperation is now alive with liver metastasis at 22 months follow-up. The remaining two patients died in the postoperative period with uncontrolled intrabdominal complications.

In five patients, the liver function test were altered in the follow-up period, showing increased values of liver enzymes. This finding was of minor clinical significance (Table 4).

\section{Patterns of tumor progression}

The initial site of tumor progression has been deter-mined in 18 patients with persistent or recurrent gastric adenocarcinoma. Intra-abdominal structures were involved in 16 cases and extra-abdominal in four cases. Two patients had a mixed recurrent pattern. Ali patients, with recurrent disease in the celiac axis had macroscopic or unresected tumor in the area. Peritoneal seeding and ascites were identified in seven patients (two as mixed failure with simultaneous bone and lung metastasis). Four patients have developed liver metastasis. Tumor recurrence has been seen in a large portion in advanced tumor stages (III and IV) and undifferentiated histologic subtypes (Table 5). No locoregional failures were seen in patients treated with primary disease.

\section{Patient outcome and survival data}

The follow-up time of the series ranges from $4+76+$ months with a median of 22 months. At the time of this analysis, 22 patients are alive and free of disease, two are alive with disease, sixteen have died with locally recurrent or metastatic cancer and eight have died of intercurrent causes. Intercurrent causes of death were: cerebellar hematoma (at necropsy) in one patient, massive gastrointestinal bleeding in four patients (two were re-operated and apparently free of abdominal tumor, and in two no precise diagnosis was made ).

Patients treated in the study protocol time period of 71 months, have an overall acturial survival rate projected at maximum follow-up time, of 39\% (Fig. 4). A subset analysis by prognostic features shows survival rates for patients with positive or negative nodal involvement, the projected survival rates are $33 \%$ and 56\%, respectively (Fig. 5). The 
combination of the worst prognostic features, that of serosal and nodal involvement, shows an actuarial survival rate of $26 \%$. In calculating these figures, the patients with recurrent nodal disease in the celiac axis were excluded. There are two long-term surviving patients $(22+$ and $65+$ months) free of detectable disease with known residual tumor after maximal resection.

\section{DISCUSSION}

The tolerance of upper abdominal organs and structures to external beam radiotherapy following gastric resection have been tested in some clinical trials reported previously $(6,10,24,35,41)$. Few events were described as major toxicities supposedly induced by radiotherapy, which implies that an acceptable clinical tolerance might be assumed from those trials, if the technical aspects involved in delivering the treatment are followed meticulously.

The information with regards to tolerance of normal tissues in clinical trials using IORT in gastric cancer patients is disperse and inconsistent $(10,17,20,25,29,36)$. The IORT technique varied the different trials which impose to be cautious at the time of comparing the end results. In several studies IORT has been used as the only radiotherapy component of the treatment program, but administering a large single fraction in the range of 28 to $35 \mathrm{~Gy}$. In this type of approach slight elevations of the serum amylase and insulin levels were described, with later normalization of these values (4). Other isolated treatment induced changes were gastric ulcer and gastrointestinal bleeding reported by the same group of investigators (27). It is uncertain as to whether the stomach or small intestine were included in the IORT field. Data from another trial using IORT as the only radiotherapy treatment component in one study are was reported by the NCI group using 25 Gy following gastrectomy but delivered in the upper abdominal structures through a multiple field adjacent fields technique (42). The study was closed with few patients in the IORT arm (10 cases), but some toxic episodes were reported among this small group, including cases of gastrointestinal bleeding (32, 43). There is no yet information available from a comparable clinical trial to the experience reviewed in this report: a moderate intraoperative single dose of radiation using an electron beam (15 Gy), plus a large external beam volume treated conventionally to $46 \mathrm{~Gy}$, as an in-tense treatment program following gastrectomy in gastric cancer patients. Large animal models have tested the tolerance of normal tissues to increasing doses of EBRT alone, IORT alone, or the combination of EBRT (50 Gy) and increasing doses of IORT $(18,34)$. With treatment combinations in the range of IORT (15 Gy) plus EBRT (46-50 Gy) the pancreas (5) large vessels (19) and bone (39) were structures that showed an acute and long-term acceptable tolerance in the dog model. In the clinical setting, the treatment program has proven to be feasible but associated to occasionally severe complications $(8,13,26,40,41)$. Gastrointestinal bleeding was observed in five instances, in which an arterioenteric fistula was documented in three cases. The pathogenesis of this event is not completely clear. A suggested theoretical explanation for the finding is the development of enteritis, bowel wall perforation, secondary intra-abdominal infection that might induce an arterial wall erosion and a subsequent fistula (14). In the present experience a case, in which a pseudoaneurysmatic change was observed in the left gastric artery stump, developed a fistula that can be attributed in pan to the IORT component of the treatment. In the present trial, the small bowel was never included in the IORT field, but the arterial 
vessels of the upper abdomen including the coeliac trunk, superior mesenteric artery and a portion of the aorta were always included in the target volume of IORT. Other aneurysmatic and/or stenotic changes were not detected in any case followed for more than 2 years after treatment. The routine CT scans performed could not show morphologic changes in these structures. The gastrointestinal bleeding episodes observed in this trial were not fully explainable on the basis of the treatment intensity employed and this was not a universal finding. Severe gastrointestinal bleeding was observed only in patients with associated enteritis. Other observations that might be interpreted as side effects from the treatment program have been vertebral collapse and liver enzymes elevations. Vertebral collapse has been described in previous reports using IORT in para-aortic spaces (40). The complication was symptomatic in all patients but improved with time, and pain was controlled by anti-inflammatory therapy. Two patients required temporary use of a cast. The rest of the mentioned treatment complications were not severe in character and tend to improve or stabilize with time. In five cases, liver hemangiomas simulated liver metastasis. Nevertheless, the possible relationship between the development of hemangiomas as treatment related complications is at the present moment unexplainable. Patients with liver enzymes elevated values had simultaneous symptoms of enteritis.

Nine patients required reoperations in the follow-up period: 6 due to related complications, one to tumor progression and two to unrelated processes to their disease and/ or treatment. One patient survived 22 months following an emergency laparotomy for arterio-enteric fistula with no further bleeding. All patients requiring surgical procedures for benign processes or non-treatment related complications recovered without morbidity.

The patterns of tumor recurrence are particularly difficult to assess in post-resected gastric cancer patients. Landry et al. (30) recently reported that $38 \%$ of all initial sites of disease recurrence occur in intra-abdominal structures. In most cases, tumor progression was noted to involve multiple concurrent zones within the abdomen. In our experience, local recurrence was confined to patients with unresectable disease in the celiac axis. Sites of failure included unresectable nodal area in the celiac axis ( 3 out of 4 cases) and mucosal anastomosis (one case). Seven cases of peritoneal seeding were detected in patients with poor prognostic features. Extra-abdominal recurrence was a rare clinical finding. A compared discussion with previous adjuvant gastric cancer trials is limited by the lack of detailed analysis of locoregional pattern of progression.

The analysis of survival is a particular delicate aspect in this type of trials. The overall survival of the group is projected for the entire group to the maximum follow-up (76 months) as 39\%. In eight patients, the cause of death was not tumor recurrence. Survival values tends to be related to pathologic prognostic features: positive or negative serosal involvement (33\% vs. 66\%, respectively), the presence or absence of nodal metastasis (33\% vs. 56\%, respectively) and postsurgical tumor residual (18\% for macroscopic residual disease vs $69 \%$ with microscopic residual). Any intent to compare the present data with previous clinical reports using IORT in gastric cancer patients will have important methological objections. The tumor staging classification has changed in the last decade, re-grouping patients with different pathologic features, and asking for certain information that will not longer be available from past analysis and even in most contemporary studies, such as the measurement of the distance between the primary tumor and the metastatic nodes (9). This will compromise our ability to compare recent 
and future survival figures with historical data. Nevertheless, it is important to remark that there are long-term surviving patients with a combination of poor prognostic features including one recurrent case with post-surgical macroscopic residual disease (7, 45)

In summary, the combination of gastrectomy, single field of intraoperative radiotherapy delivering a moderate single dose $(15 \mathrm{~Gy})$ to the upper abdominal central axis nodes, followed by a full course of external beam irradiation (46 Gy in 23 fractions, 2 Gy per fraction) to a large field encompassing the upper abdominal nodal regions and the gastric bed, is a feasible treatment approach (11). The clinical observations appears to reach the tolerance limit of the treatment intensification in this particular anatomic area. The locoregional tumor control rates are high, with no failures in patients treated for primary disease, which allows one to recommend a certain compromise to decrease the total radiation dose delivered by both treatment component s, IORT and EBRT.

\section{REFERENCES}

1. Abe, M. Intraoperative radiation therapy for gastric cancer. In: Dobelbower, R. R., Abe, M., eds. Intraoperative radiation therapy. Boca Raton FL: CRC Press; 1989:165-180.

2. Abe, M.; Takahashi, M. Intraoperative radiotherapy: The Japanese experience. Int. J. Radiat. Oncol. Biol. Phys. 7: 863-868;1981.

3. Abe, M.; Takahashi, M.; Ono, K.; Tobe, T.; Inamoto, T. Japan gastric trials in intraoperative radiation therapy. Int. J. Radiat. Oncol. Biol. Phys. 15:1431$1433 ; 1988$.

4. Abe, M. Intraoperative radiation therapy for gastrointestinal malignancy. In: De Cosse, J. J., Sherlock, P., eds. Clinical management of gastrointestinal cancer. New York, NY: Nijhoff; 1984:327-349.

5. Ahmadu-Suka, F.; Gillette, E. L.; Vithrow, S. J.; Husted, P. W.; Nelson, A. W.; Whiteman, C. E. Pathologic response of the pancreas and duodenum to experimental intraoperative irradiation. Int. J. Radiat. Oncol. Biol. Phys. 14:1197-1204;1988.

6. Allum, W. H.; Hallíssey, M. T.; Ward, L. C.; Hockey, M. S. A controlled, prospective, randomized trial of adjuvant chemotherapy or radiotherapy in resectable gastric cancer: Interim report. Bristish Stomach Cancer Group. Br. J. Cancer 60:739-744;1989.

7. Audeh, M. W.; Carlson, R. W.; Jacobs, C. D.; Dunphy, E. P.; Davis, T. E.; Coleman, C. N. Long-term survival in advanced gastric carcinoma following combined modality therapy: The Stanford University experience. Proc. Ann. Meet. Am. Soc. Clin. Oncol. 8:A458;1989.

8. Avizonis, V. N.; Sause, W. T.; Noyes, D. Morbidity and mortality associated with intraoperative radiotherapy. J. Surg. Oncol. 41:240-245;1989.

9. Beahrs, O. H.; Hensen, D. E.; Hutter, R. V. P.; Myers, M. H. Manual for staging of cancer, 3rd. edition. Philadelphia, PA: J. B. Lippincott Co; 1988.

10. Bleiberg, H.; Goffin, J. C.; Dalesio, O.; Buyse, M.; Pector, J. C.; Gignovx, M.; Roussel, A.; Samana, G.; Michel, J.; Guard, A. Adjuvant radiotherapy and chemotherapy in resectable gastric cancer. A randomized trial of the gastrointestinal tract cancer cooperative group of the EORTC. Eur. J. Surg. Oncol. 15:539-543;1989. 
11. Calvo, F. A.; Hanks, G. E. International clinical trials in radiation oncology. Intraoperative trials. Int. J. Radiat. Oncol. Biol. Phys. 14:S111-S117;1988.

12. Calvo, F. A.; Henriquez, 1.; Santos, M.; Escude, L.; Ortiz de Urbina, D.; Hernandez, J. L.; Zornoza, G.; Ahenke, A.; Voltas, J. Intraoperative and external beam radiotherapy in advanced resectable gastric cancer: Technical description and preliminary results. Int. J. Radiat. Oncol. Biol. Phys. 17:183-189;1989.

13. Cromack, D. T.; Maher, M. M.; Hoekstra, H.; Kinsella, T. J.; Sindelar, W. F. Are complications in intraoperative radiotherapy more frequent than in conventional treatment? Arch. Surg. 124:229-234;1989.

14. Estrada, F. P.; Tachovsky, T. J.; Orr, R. M.; Boylan, J. J.; Kram, B. W. Primary aortoduodenal fistula following radiotherapy. Surg. Gyn. Obstet. 156:646$650 ; 1983$.

15. Gastrointestinal Tumor Study Group. A comparison of combination chemotherapy and combined modality therapy for locally advanced gastric carcinoma. Cancer 49:1771-1777;1982.

16. Gastrointestinal Tumor Study Group. The concept of locally advanced gastric cancer. Effect of treatment on outcome, Cancer 66:2324-2330;1990.

17. Gerard, J. P.; Sentenac, I.; Gilly, F.; Romestaing, P.; Rocher, F.; Salerno, N.; Descos, L.; Vignal, J.; Braillon, G. Intra-operative radiotherapy for carcinoma of the stomach with the Lyon intraoperative system. A series of 27 patients. In: Abe, M., Takahashi, M., eds. Intraoperative radiation therapy. New York, NY: Pergamon Press; 1991:195-196.

18. Gillette, E. L.; McChesney-Gillette, S.; Powers, B. E.; Thames, H. D. Potential for a therapeutic gain for IORT combined with EBRT. In: Abe, M., Takahashi, M., eds. Intraoperative radiation therapy. New York, NY: Pergamon Press; 1991:12-14.

19. Gillette, E. L.; Powers, B. E.; McChesney, S. L.; Park, R. D.; Withrow, S. J. Response of aorta and branch arteries to experimental intraoperative irradiation. Int. J. Radiat. Oncol. Biol. Phys. 17:1247-1255;1989.

20. Guillemin, F.; Malissard, L.; Aletti, P.; Bey, P.; Verhaeghe, J. L.; Godfrin, P. Y. Intra-operative radiation therapy for carcinoma of the stomach. A five year experience. Pilot study. In: Abe, M., Takahashi, M., eds. Intraoperative radiation therapy. New York, NY: Pergamon Press; 1991: 199-200.

21. Gunderson, L. L.; Hoskins, B.; Cohen, A. M.; Kaufman, S.; Wood, W.; Carey, R. Combined modality treatment of gastric cancer. Int. J. Radiat. Oncol. Biol. Phys. 9:965-975;1982.

22. Gunderson, L. L.; Martenson, J. A. Gastrointestinal tract radiation tolerance. Front. Radiat. Ther. Oncol. 23;277- 298;1989 .

23. Gunderson, L. L.; Sosin, H. Adenocarcinoma of the stomach: Areas of failure in a reoperation series (second or symptomatic look). Clinical pathologic correlation and implications for adjuvant therapy. Int. J. Radiat. Oncol. Biol. Phys. 8:1-11;1982.

24. Gez, E.; Sielkes, A.; Vablonski, P. T. Combined 5-FU and radiation therapy following resection of locally advanced gastric carcinoma. J. Surg. Oncol. 31:139-142;1986.

25. Hanks, G. E.; Owens, J.; Won, M.; Noyes, D.; Sause, W.; Lanciano, R. M. Outcome of gastric cancer treated with surgery, intraoperative electron beam radiation and postop external beam irradiation in RTOG \#8504. Proc. American Cancer Society 75th Anniversary, Montreal 16, May 1991. 
26. Hoekstra, H. J.; Restrepo, C.; Kinsella, T. J.; Sindelar, W. F. Histopathological effects of intraoperative radiotherapy on pancreas and adjacent tissues: A postmortem analysis. J. Surg. Oncol. 37:104-108;1988.

27. Honda, K.; Inamoto, T.; Shibamoto, Y. Intraoperative adiation therapy for gastric cancer (Abstract). Presented at the Second International Symposium on Intraoperative Radiation Therapy, September 11-14, 1988, Innsbruck, Austria. Strahlenter. Onkol. 165:765-790;1989.

28. Horvath, W.; Pipoly, G.; Krupp, K. Improved survival in gastric cancer with postoperative chemo-radiotherapy. Proc. Ann. Meet, Am. Soc. Clin. Oncol. 9:A 428; 1990 .

29. Kramling, H. J.; Willich, N.; Denecke, H.; Grab, J.; Schilberg, F. W. Prospective randomized study on IORT for resectable gastric carcinoma. In: Abe, M., Takahashi, M., eds. Intraoperative radiation therapy. New York, NY: Pergamon Press; 1991:192-194.

30. Landry, J.; Tepper, J. E.; Wood, W. C.; Orlow, E.; Koerner, F.; Sullinger, J. Patterns of failure following curative resection of gastric carcinoma. Int. J. Radiat. Oncol. Biol. Phys. 19:1357-1362.

31. MacDonald, J. S.; Steele, G.; Gunderson, L. L. Cancer of the Stomach. In: De Vita, V. T., Hellman, S., Rosenberg, S. A., eds. Cancer. Principles and practice of oncology. Philadelphia, PA: J. B. Lippincott Co.; 1989:765-799.

32. Maher, M. M.; Cromack, D. T.; White, D. E.; Smith, R.; Kinsella, T. J.; Sindelar, W. F. Complications of intraoperative radiation therapy (Abstract). Presented at the Second International Symposium on Intraoperative Radiation Therapy, September 11-14, 1988, Innsbruck, Austria. Strahlenter Onkol. 165:765-790;1989.

33. Mazzeo, F.; Mozzillo, N.; Forestieri, P. Cancer of the stomach. In: Veronesi, V., ed. Surgical oncology. A European handbook. Heidelberg: Springer-Verlag; 1989:544-577.

34. McChesney-Gillette, S.; Gillette, E. L.; Powers, B. E.; Le Couteur, R. A.; Park, R. D.; Withrow, S. J. Late normal tissue response after intraoperative therapy (IORT) alone and combined with external beam radiotherapy (EBRT ). In: Abe, M., Takahashi, M., eds. Intraoperative radiation therapy. New York, NY: Pergamon Press; 1991:399-400.

35. Moertel, C. G.; Chilos, D. S.; Fallon, J. R. Combined 5- fluorouracil and radiation therapy as a surgical adjunct for poor prognosis gastric carcinoma. J. Clin. Oncol. 2:1249-1254;1984.

36. Noyes, R. D.; Weiss, S. M.; Sause, W.; Krall, J.; Owens, J.; Hanks, G.; Hoffmann, J.; Thomson, J.; Calkins, A.; Tepper, J. Surgical complications of intraoperative radiotherapy: The Radiation Therapy Oncology Group experience. In: Abe, M., Takahashi, M., eds. Intraoperative radiation therapy. New York, NY: Pergamon Press; 1991:393-395.

37. O'Connell, M. J.; Gunderson, L. L.; Moertel, C. G.; Kvols, L. K. A pilot study to determine clinical tolerability of intensive combined modality therapy for locally unresectable gastric cancer. Int. J. Radiat. Oncol. Biol. Phys. 11:18271831;1985.

38. Papachristou, D. H.; Fortner, J. G. Local recurrence of gastric adenocarcinoma after gastrectomy. J. Surg. Oncol. 18: 47-53;1981.

39. Powers, B. E.; Gillette, E. L.; McChesney, S. L.; le Couteur, R. A. Bone necrosis and tumor induction following experimental intraoperative irradiation. Int. J. Radiat. Oncol. Biol. Phys. 17:559-567;1989. 
40. Roussel, A.; De Ranieri, J.; Crouet, H.; Allain, P.; Souloy, J.; Desdoits, J. M.; Bovet, A. Late complications after intraoperative radiation therapy in para-aortic node area. In: Abe, M., Takahashi, M., eds. Intraoperative radiation therapy. New York, NY: Pergamon Press; 1991:396-398.

41. Schein, P. A comparison of combination chemotherapy and combined modality therapy for locally advanced gastric carcinoma. Cancer 49:1771-1777;1982.

42. Sindelar, W. F.; Kinsella, T. J. Randomized trial of resection and intraoperative radiotherapy in locally advanced gastric cancer (Abstract) Proc. Am. Soc. Clin. Oncol. 6:91;1987.

43. Sindelar, W. F.; Kinsella, T. J.; Hoekstra, H. J.; Tochner, Z.; Smith, R.; Glatstein, E. Treatment complications in intraoperative radiotherapy (Abstract). Int. J. Radiat. Oncol. Biol. Phys. 11 (Suppl.):117;1985.

44. Slot, A.; Meerwaldt, J. H.; Van Putten, W. L.; Treurniet-donker, A. D. Adjuvant postoperative radiotherapy for gastric carcinoma with poor prognostic signs. Radiother. Oncol. 16:269-274;1989.

45. Song, S.; Chen, G. Evaluation of intraoperative radiotherapy for gastric carcinoma. Analysis of 247 patients. In: Abe, M., Takahashi, M., eds. Intraoperative radiation therapy. New York, NY: Pergamon Press; 1991:190191.

46. Thompson, F. B.; Robins, R. F. Local recurrence following subtotal resection for gastric carcinoma. Surg. Gynecol. Obstet. 95:341-344;1952. 


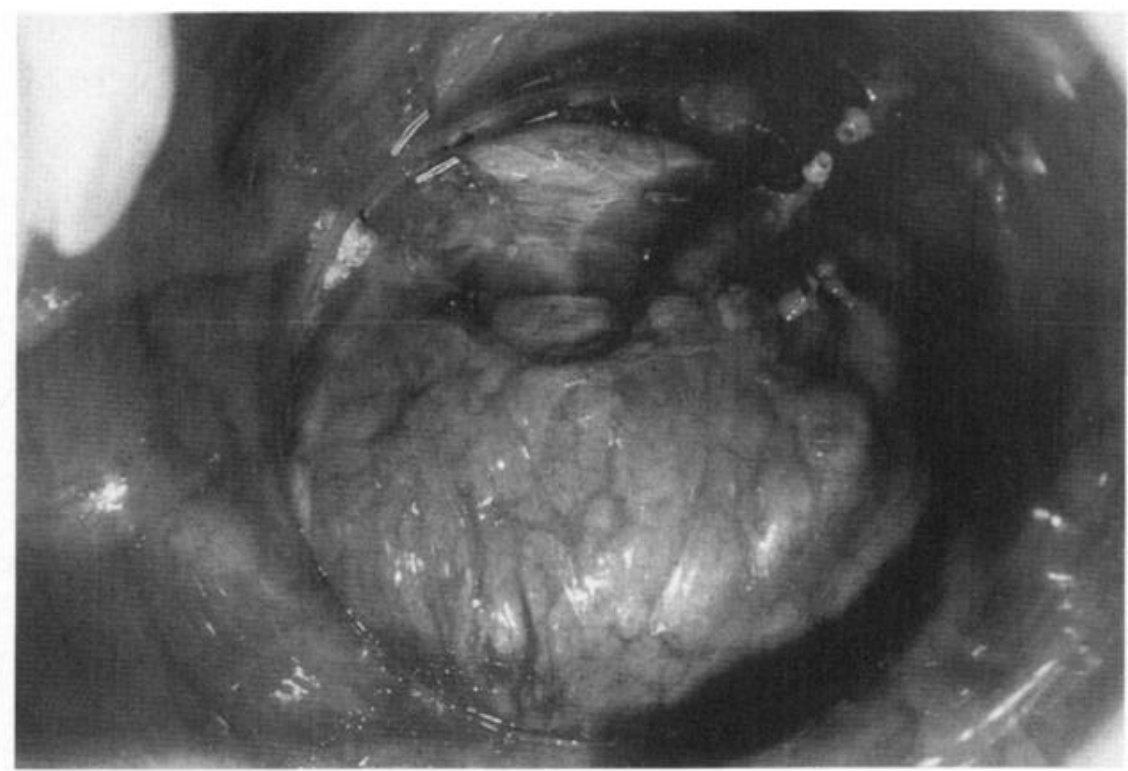

Figure 1. View of the IORT target field through the cone. Notice the left gastric artery stump in the right upper comer of the image.

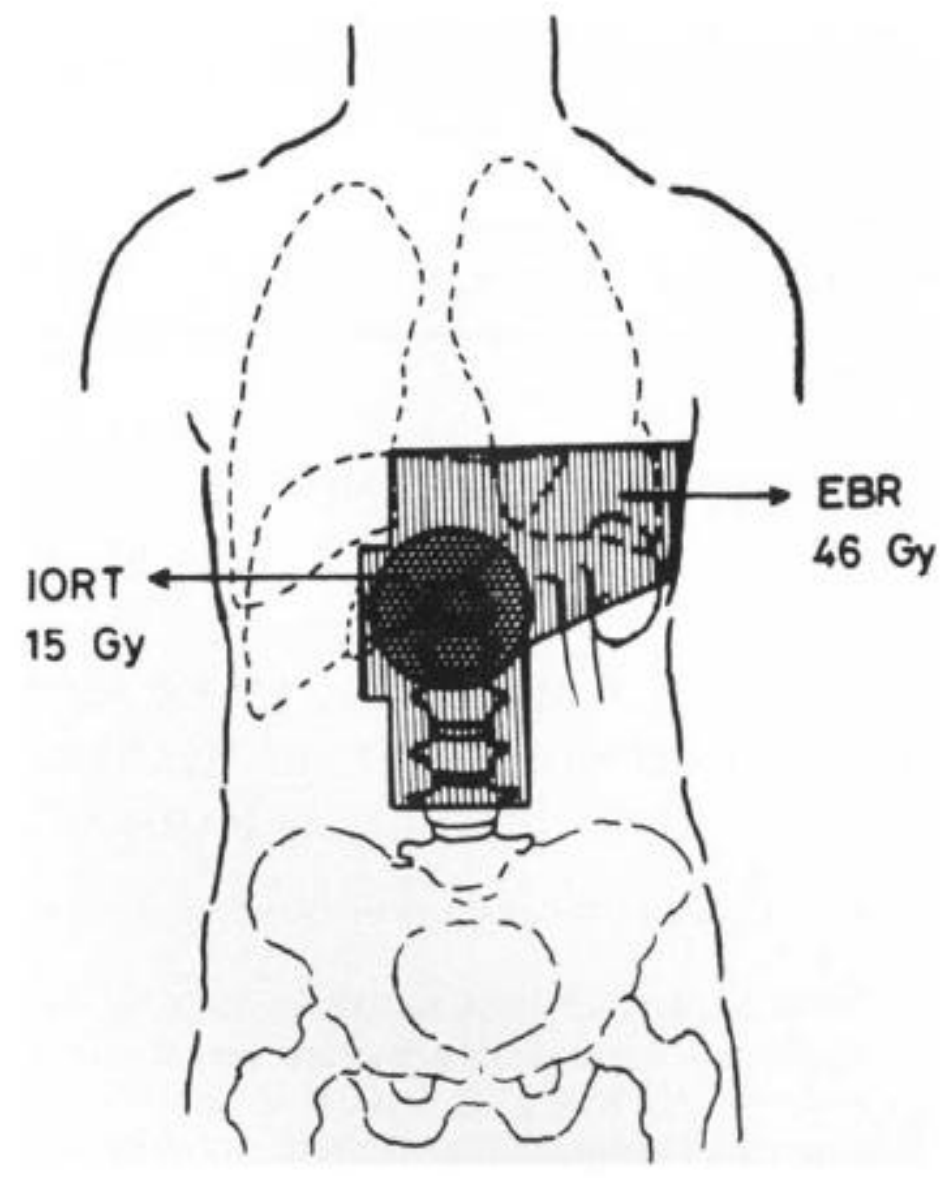

Figure 2. Diagram of the integration of IORT plus external beam irradiation volume. 


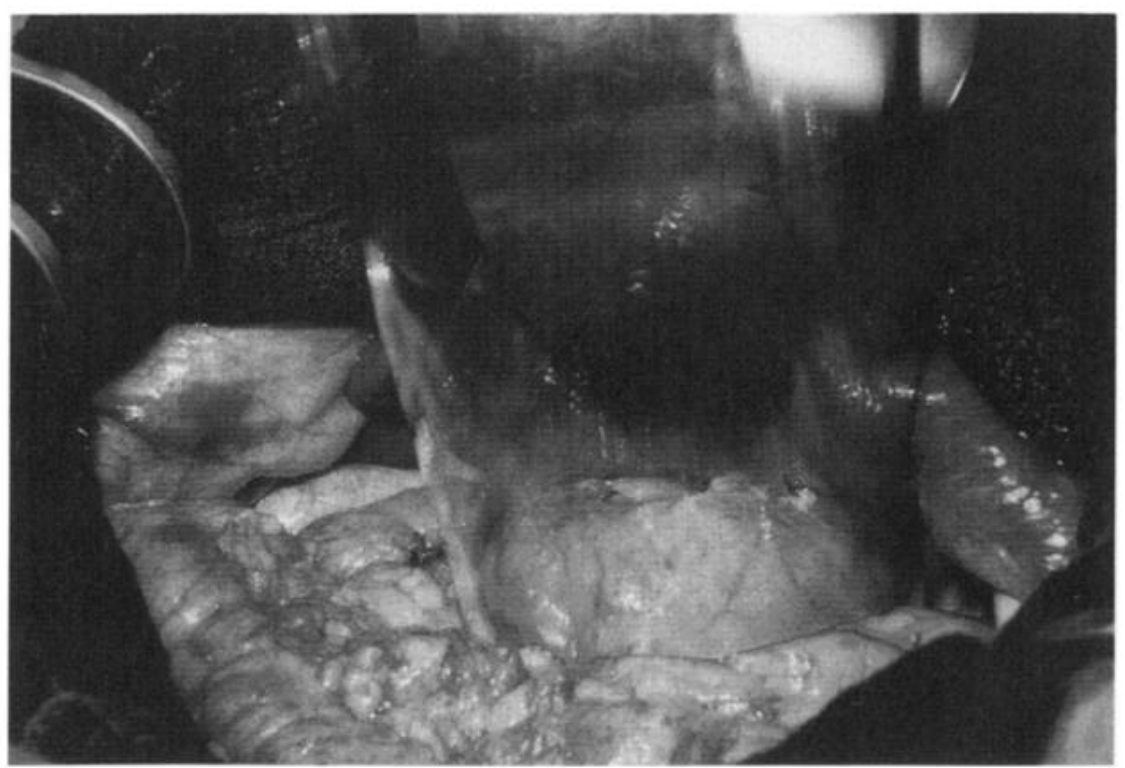

Figure 3. IORT cone positioned. Notice that the upper abdominal mobile structures are retracted from the treatment field.

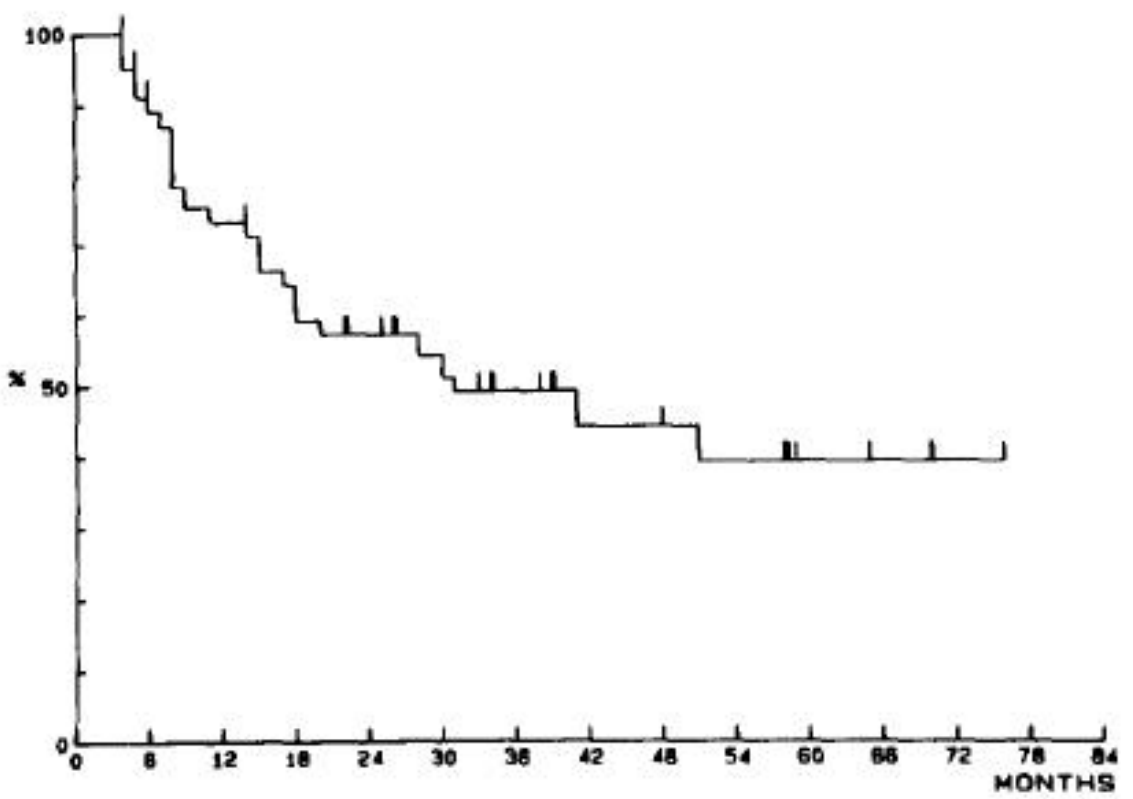

Figure 4. Overall actuarial survival curve for the entire group of gastric cancer patients treated with IORT. 


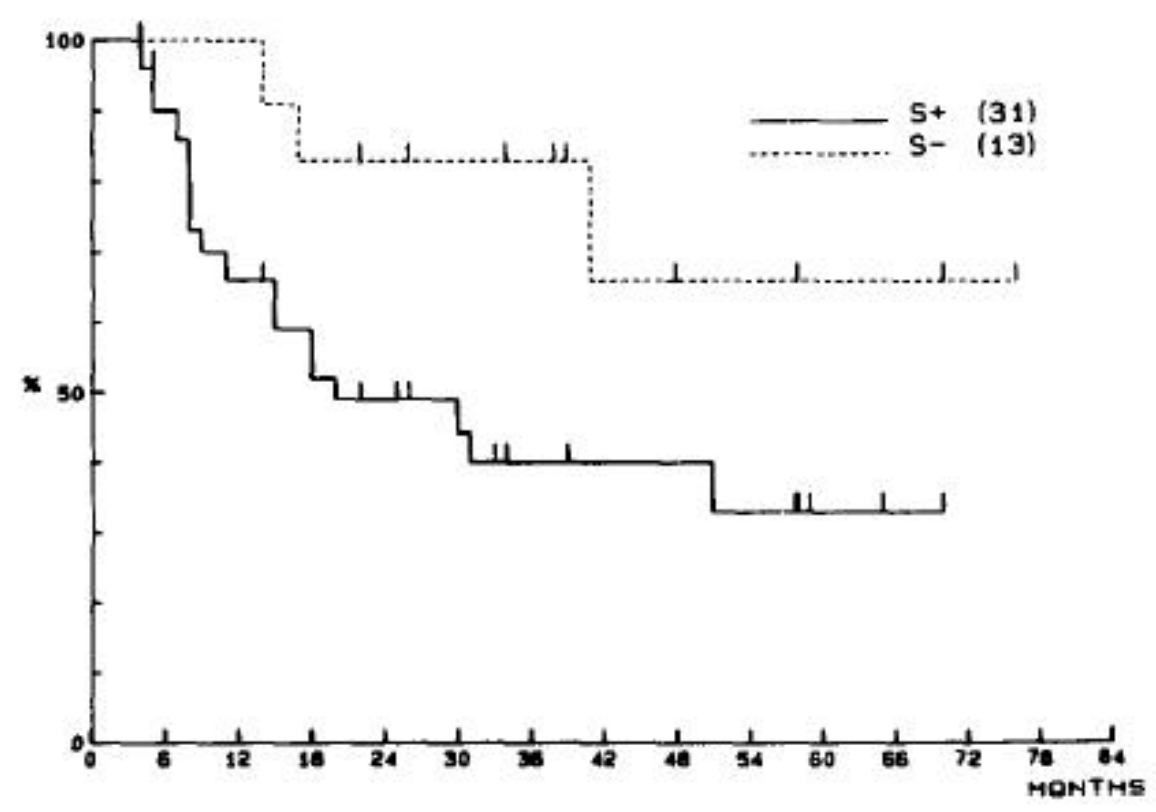

Figure 5. Comparative actuarial survival curves regarding presence or absence of serosal involvement. Patients with recurrent nodal masses are excluded from this analysis. 


\begin{tabular}{|l|c|c|}
\hline \multicolumn{3}{|c|}{ Table 1. Patients characteristic } \\
\hline Patients & No. & $\%$ \\
\hline Total number & 48 & 100 \\
\hline Age (years) & & \\
\hline Range & $34-76$ & \\
\hline Median & 58 & \\
\hline Sex & & \\
\hline Male & 35 & 73 \\
\hline Female & 13 & 27 \\
\hline Karnofsky & & \\
\hline$<70 \%$ & 11 & 23 \\
\hline$>70 \%$ & 37 & 77 \\
\hline Symptoms & & \\
\hline Pain & 25 & 52 \\
\hline Weight Loss & 10 & 21 \\
\hline GI bleeding & 7 & 14 \\
\hline Vomiting & 6 & 12 \\
\hline Dysphagia & 5 & 10 \\
\hline Anemia & 4 & 8 \\
\hline
\end{tabular}

\begin{tabular}{|l|c|c|}
\hline \multicolumn{3}{|c|}{ Table 2. Tumor characteristics } \\
\hline Tumor & No. & $\%$ \\
\hline Histology & & \\
\hline Adenocarcinoma & 46 & 96 \\
\hline Well/moderately differentiated & 15 & 31 \\
\hline Poorly differentiated/diffuse & 31 & 65 \\
\hline Other & 2 & 4 \\
\hline Location & & \\
\hline Proximal (cardias- fornix) & 6 & 13 \\
\hline Central (corpus) & 5 & 10 \\
\hline Distal (antrum-pilorum) & 19 & 40 \\
\hline Anastomotic site (stump) & 7 & 15 \\
\hline Celiac axis relapse & 4 & 8 \\
\hline Proximal + central & 4 & 8 \\
\hline Central + distal & 2 & 4 \\
\hline Proximal + central + distal & 1 & 2 \\
\hline Nodes & & \\
\hline Positive & 27 & 56 \\
\hline Negative & 21 & 44 \\
\hline Serosa & & \\
\hline Involved & 31 & 70 \\
\hline Uninvolved & 13 & 30 \\
\hline Stage & & \\
\hline I-I & 16 & 33 \\
\hline III & 19 & 40 \\
\hline IV & 13 & 27 \\
\hline
\end{tabular}




\begin{tabular}{|l|c|c|}
\hline \multicolumn{3}{|c|}{ Table 3. Treatment characteristics } \\
\hline Treatment & No. & \% \\
\hline Surgery & & \\
\hline Total gastrectomy & 36 & 7 \\
\hline Partial gastrectomy & 8 & 17 \\
\hline Tumor exposure & 4 & 8 \\
\hline IORT & & \\
\hline Cone size & & \\
\hline 5-6 cm & 8 & 17 \\
\hline $7-8$ cm & 25 & 52 \\
\hline 9-10 cm & 17 & 35 \\
\hline Number of fields & & \\
\hline Single & 47 & 98 \\
\hline Multiple & 1 & 2 \\
\hline Electron energy & & \\
\hline 6-9 Mev & 18 & 37 \\
\hline $12-15 \mathrm{MeV}$ & 27 & 56 \\
\hline $18-20 \mathrm{MeV}$ & 5 & 10 \\
\hline Total dose & & \\
\hline 10 Gy & 3 & 6 \\
\hline 15 Gy & 46 & 96 \\
\hline 20 Gy & 1 & 2 \\
\hline External beam RT & & \\
\hline Preoperative & 3 & 8 \\
\hline Postoperative & 5 & 81 \\
\hline Not given & & 11 \\
\hline Chemotherapy & & 27 \\
\hline
\end{tabular}


Table 4. Toxicity and complications

\begin{tabular}{|l|c|c|}
\hline Observations & No. & \% \\
\hline Acute & & \\
\hline Pneumonia & 5 & 10 \\
\hline Suture dehiscence & 1 & 2 \\
\hline Abdominal-pulmonary/abcess & 5 & 10 \\
\hline Gastrointestinal bleeding & 1 & 2 \\
\hline Sepsis & 1 & 2 \\
\hline Pulmonary emboli & 1 & 2 \\
\hline Pancreatic fistula & 3 & 6 \\
\hline Late & & \\
\hline Vertebral collapse & 6 & 12 \\
\hline Esophageal dilatations & 3 & 6 \\
\hline Liver infarction & 1 & 2 \\
\hline Cholangitis & 1 & 2 \\
\hline Fistula & 3 & 6 \\
\hline Enteritis & 9 & 19 \\
\hline Gastrointestinal bleeding & 5 & 10 \\
\hline Liver function test altered & 5 & 10 \\
\hline Reoperations (laparotomies) & 9 & 19 \\
\hline$*$ Six treatment related. & \multicolumn{2}{|l}{} \\
\hline \multicolumn{2}{|l|}{}
\end{tabular}

\begin{tabular}{|c|c|c|c|c|c|c|}
\hline \multicolumn{7}{|c|}{ Table 5. Patterns of disease progression } \\
\hline & \multicolumn{6}{|c|}{ Site of progression } \\
\hline & \multicolumn{3}{|c|}{ Intra-abdominal } & \multicolumn{3}{|c|}{ Extra-abdominal } \\
\hline Tumor factors & $\mathbf{C A}$ & $\mathbf{P}$ & $\mathbf{L i}$ & $\mathbf{N}$ & $\mathbf{L U}$ & $\overline{\mathbf{B}}$ \\
\hline \multicolumn{7}{|l|}{ Stage } \\
\hline I-II & - & - & 1 & - & 1 & - \\
\hline III & 2 & 5 & 1 & 1 & - & - \\
\hline IV & 3 & 2 & 2 & 1 & - & 1 \\
\hline \multicolumn{7}{|l|}{ Histology } \\
\hline Well/moderately differentiated & 2 & 2 & - & - & 1 & - \\
\hline Undifferentiated & 3 & 5 & 4 & 2 & - & 1 \\
\hline No. patients (18) & 5 & 7 & 4 & 2 & 1 & 1 \\
\hline
\end{tabular}

